\title{
PEDAGOGIA CRÍTICA COMO PRÁXIS MARXISTA HUMANISTA: PERSPECTIVAS SOBRE SOLIDARIEDADE, OPRESSÃO, E REVOLUÇÃO
}

\author{
Sabrina Fernandes ${ }^{1}$
}

\begin{abstract}
RESUMO: Este artigo pretende explorar a fundamentação teórica e filosófica da pedagogia crítica no Humanismo Marxista através do conceito de práxis (revolucionária) e através de uma investigação sobre o papel da solidariedade na superação da opressáo. Mais precisamente, ele examina a vasta obra teórica sobre o Humanismo Marxista e como suas perspectivas sobre a opressão, alienação, libertação e revolução são essencialmente ligadas ao conceito de práxis, que é central para a pedagogia crítica de Paulo Freire. A solidariedade, que normalmente é apresentada de forma tangencial à discussáo, torna-se um dos pontos focais do argumento, enfatizando totalidade e coletividade em uma visáo de libertação destinada à abolição e superação (aufheben).
\end{abstract}

Palavras-chave: Humanismo marxista. Pedagogia crítica. Práxis. Solidariedade. Libertação.

\section{Critical PEDAgogy as Humanistic MARXIST PRAXIS: PERSPECTIVES ON SOLIDARITY, OPPRESSION, AND REVOLUTION}

ABSTRACT: This article aims to explore the theoretical and philosophical basis of critical pedagogy in Marxist Humanism by analyzing the concept of (revolutionary) praxis and investigating the role of solidarity in overcoming oppression. More to the point, it attempts to examine the extensive theoretical work on Marxist Humanism and to find out how the visions about oppression, alienation, liberation and revolution are essentially linked to the concept of praxis, which is central to the critical pedagogy of Paulo Freire. Solidarity, which is usually presented tangentially to the discussion, becomes one of the key points of the argument, emphasizing totality and community when referring to liberation aimed to abolition and overcoming (aufheben).

Keywords: Marxist Humanism. Critical pedagogy. Praxis. Solidarity. Liberation.

\footnotetext{
${ }^{1}$ Carleton University, Department of Sociology and Anthropology - Ottawa, Ontario, Canadá. E-mail de contato: sabrina.fernandes@carleton.ca DOI: 10.1590/ES0101-73302016140795
} 


\title{
LA PÉDAgOGIE CRITIQUE COMME PRAXIS MARXISTE HUMANISTE: PERSPECTIVES SUR LA SOLIDARITÉ, L'OPPRESSION ET LA RÉVOLUTION
}

\begin{abstract}
RESUME: Cet article vise à explorer les fondements théoriques et philosophiques de la pédagogie critique dans l'humanisme marxiste à travers le concept de praxis (révolutionnaire) et par le biais d'une enquête sur le rôle de la solidarité pour surmonter l'oppression. Plus précisément, il examine le vaste travail théorique sur le Humanisme marxiste et comment les points de vue sur l'oppression, l'aliénation, la libération et la révolution sont essentiellement liées à la notion de praxis, qui est au coeur de la pédagogie critique de Paulo Freire. Solidarité, habituellement présenté tangentiellement à la discussion, devient l'un des points centraux de l'argument, avec l'accent mis sur la totalité et de la communauté dans une vision de libération orientée vers l'abolition et la libération (aufheben).
\end{abstract}

Mots-clés: Humanisme marxiste. La pédagogie critique. Praxis. Solidarité. Libération.

A

pedagogia crítica freiriana procede do trabalho do pedagogo brasileiro Paulo Freire e consiste de um conjunto de teorias e práticas fundadas na educação como forma de emancipação e um projeto para a libertação política e social para um mundo sem opressão. O legado de Paulo Freire não é apenas entrelaçado com o do Humanismo Marxista, mas também oferece introspecções valiosas sobre o papel da práxis no Humanismo Marxista. Freire faz referências teóricas diretas à literatura Marxista, incluso o próprio Marx, mas frequentemente demonstra certa incoerência ao misturar e combinar uma variedade de conceitos que considera importantes para a pedagogia crítica mesmo se eles originam de posiçóes teóricas diferentes ou conflitantes (tais como referências a Karl Popper e a sociedade aberta liberal, mas também a Georg Lukács e Erich Fromm). Não obstante, a pedagogia da libertação de Freire está enraizada nos princípios fundamentais do humanismo marxista, uma vez que visa superar a opressão através de um processo de conscientização crítica fundamentada na unidade dialética entre teoria e prática transformadoras.

A pedagogia crítica como um projeto de liberdade se dá através da práxis autêntica: a relação dialética entre ação e reflexão (FREIRE, 2005, p. 42). A verdadeira reflexão deve sempre levar à ação; e a ação só está envolvida em uma práxis autêntica, no lugar de um ativismo simples, se os seus resultados são objetos da reflexão crítica (FREIRE, 1970, pp. 52-53). O aspecto revolucionário da práxis não reside na sua relevância como uma teoria da ação, mas na quebra da dicotomia do pensamento e ação, exigindo que esses ocorram simultaneamente e dialetica- 
mente, a fim de proporcionar uma leitura da realidade e suas contradiçóes que vise à criação de alternativas libertadoras (FREIRE, 2005, p. 146). Embora Freire não fale de solidariedade extensivamente em uma capacidade teórica, seu trabalho indica a importância da mesma. Portanto, este trabalho tem dois objetivos. Primeiro, ele destaca a forma como os processos transformadores de conscientização e práxis libertadora estão ligados à solidariedade e à superação da lógica binária da opressão através de uma visão dialética do oprimido e opressor ${ }^{1}$. Em seguida, ele passa a ligar estes processos à fundamentação teórica da práxis pedagógica crítica no Humanismo Marxista.

\section{Pedagogia crítica freiriana e a luta contra a opressão}

As reflexões teóricas de Paulo Freire muitas vezes se baseiam no duo oprimido/opressor, estabelecidos em relação ao capitalismo e opressão de classe. No entanto, Freire não vê isso como uma relação binária, como Peter Mayo explica, argumentando que "as relações entre opressor e oprimido sempre foram apresentadas por Freire como dialéticas” (MAYO, 2004, p. 94, minha tradução). Já que a visão de Freire da libertação dos oprimidos se dá dentro do contexto marxista, a libertação no cerne da pedagogia crítica implica não apenas a liberdade no sentido democrático, mas a liberdade "da relação da contradição dialética" ou de um lugar de consciência incoerente (e desumanizada), onde os oprimidos se encontram (ALLMAN, 1999, pp. 89-90). É possível que o caráter de oposição da língua possa ocultar o processo dialético que ocorre no espaço entre o opressor e o oprimido; no entanto, como Allman explica, a oposição ainda é caracterizada dentro da relação dialética entre oprimidos e opressores, principalmente devido ao fato de que dentro dessa contradição uma parte adversária da unidade não podem existir da mesma forma a não ser como posicionada em relação à outra parte (ALLMAN, 1999, p. 88). A relação dialética entre oprimido e opressor é o que constitui as suas posiçóes e os coloca em contradição. Libertação, portanto, consiste em superar a relação de opressão, a fim de eliminar esta contradição.

A pedagogia crítica vê a opressão como altamente complexa, especialmente porque reconhece a opressão como um lugar de incoerência e a libertação como um processo de coerência. Através da solidariedade, uma pessoa trabalha por um objetivo particular, uma vocação ontológica, que une uma vida crítica ao alcance de uma maior coerência e humanização (MAYO, 2004, pp. 93-94). A busca por coerência requer a conscientizaçáo de seu próprio "inacabamento" e posicionamento entre várias posições, sustentando o reconhecimento de que um pode ser o oprimido em um contexto e o opressor em outro e, ao mesmo tempo, enfrentar a opressão de forma diferente interna e externamente. Essa multiplicidade não é uma consequência simples da interseccionalidade que existe ao lidar com várias expressóes de opressão e desigualdade, mas existe como um estado de 
múltiplos posicionamentos que faz de alguém, de acordo com Freire, incoerente e em necessidade de uma práxis transformadora para enfrentar a consciência e prática opressoras no processo de conscientizaçâo. Para emancipar-se, primeiro é necessário confrontar a incoerência e "expulsar" a consciência opressora vivendo dentro da consciência oprimida (FREIRE, 2005, p. 164; TORRES, 1979, p. 14). Isso é possível graças à formação de uma unidade dialética entre subjetividades e objetividades, em vez de uma dualidade ou binário (TORRES, 1979, p. 44). Trata-se de um movimento do objeto para o sujeito.

Quando Freire fala da dualidade que os oprimidos encaram por também "hospedarem" o opressor (ou a sua imagem), ele não está se referindo apenas ao impacto da opressão sobre a consciência e como ela nutre uma visão derrotista, colonizada e fatalista do mundo, mas ele está também (embora em menor grau) reconhecendo que o oprimido e o opressor não são seres completos e coerentes formados independentemente de experiências e de agência como um teria em leituras estruturalistas ortodoxas (FREIRE, 2005, p. 54). Na verdade, já que a agência é um elemento primordial na práxis e a capacidade e a motivação para buscar um caminho libertador e humanizador, ela também deve desempenhar um papel dialético relativo à estrutura opressiva na relação entre oprimidos e opressores. Sem agência, a libertação se torna uma meta inatingível e qualquer tentativa de pensar sobre o mundo resulta em fatalismo. Portanto, a agência complementa a diversidade de formas de opressão, dominação e desigualdade, desempenhando um papel nos diferentes graus de opressão que são promulgados e vividos por pessoas diferentes. Para Freire, qualquer tentativa de abstrair seres humanos do impacto da realidade e da história (pessoal e mundial) e as nuances oferecidas por ela acaba dicotomizando-os em relação ao mundo e leva à alienação (TORRES, 1979, p. 18). É o reconhecimento da complexidade e as relaçóes dialéticas que permite uma pedagogia problematizadora capaz de cultivar a consciência crítica, em oposição a uma visão estruturalista desumanizante que reifica pessoas reais de acordo com as funçóes de opressor e oprimido.

A pedagogia crítica freiriana é um projeto humanista revolucionário de emancipação que tem como premissa a "vocação ontológica para se tornar humano", onde o oprimido é o agente de humanização universal (ARONOWITZ, 1993, pp. 13-14). Trata-se de superar a contradição das relaçóes oprimido-opressor; uma tarefa Freire argumenta que deve ser realizada pelos oprimidos. Ele escreve: "Para que esta luta tenha um significado, os oprimidos não devem, na tentativa de recuperar a sua humanidade (que é uma forma de criá-la), tornarem-se por sua vez opressores dos opressores, mas sim restauradores da humanidade de ambos. Essa, então, é a grande tarefa humanista e histórica dos oprimidos: libertarem a si e aos seus opressores" (FREIRE, 1970, p. 28). Na práxis da busca pela liberdade, os oprimidos devem lutar juntos com aqueles com quem estão em solidariedade, em um ato de amor e generosidade (FREIRE, 2005, p. 41). Isso engloba tanto a compreensão mais geral dos 
oprimidos em solidariedade entre si, unidos através de sua luta e buscando força nesta unidade, bem como a proposta mais radical de estender solidariedade também ao opressor (FREIRE, 2005, p. 200). Sem esse novo entendimento, os oprimidos recém-libertados arriscam tornarem-se opressores e reproduzirem a natureza totalizante da realidade opressiva, permanecendo presos dentro da lógica da opressão. Portanto, esse ato de solidariedade deve ser afetivo no modo em que requer ousadia (e amor para com a humanidade) por parte dos oprimidos envolvidos na mudança da realidade, mas também envolve elementos conscientes fundamentados na reflexão crítica sobre o mundo. O papel da consciência crítica é combater o desalinhamento entre o pensamento e a prática, que estão sujeitos à consciência, ao reconhecimento, e à agência.

A necessária consideração a ser feita é que a emancipação que Freire discute é de uma natureza dupla: ela tem lugar na consciência do indivíduo (e/ou grupo) e, por meio da unidade teórica-prática dialética corporificada na práxis, também ocorre materialmente no desmantelamento direto de estruturas opressivas. Isto implica em um estado contraditório entre consciência e atividade antes da abolição da opressão e exploração. Antonio Gramsci demonstra essa possibilidade de uma dupla consciência e existência contraditória em sua explicação sobre a existência de duas consciências teóricas no trabalhador: "aquela que está implícita na sua atividade e que realmente o une com todos os seus companheiros de trabalho na transformação prática do mundo e uma superficial, aquela 'explícita' que herdou do passado" (GRAMSCI, 2007, p. 330). É por isso que a compreensão da transformação gradual é tâo importante para incentivar o ponto de vista da consciência crítica como práxis, em vez de uma mudança brusca e mecânica dos acontecimentos. Freire explica esta distinção em relação ao impacto contraditório da dominação sobre a consciência oprimida e opressora:

Não há dominação que não produza nos dominantes e nos dominados, posiçóes e atitudes, valores e formas de leitura do mundo que são contrários uns aos outros. Ninguém, nenhuma pessoa, nenhuma classe, nenhum grupo sob dominação até ontem e demonstrando um comportamento ambivalente e duplo, passa a ser diferente hoje. Um novo homem e uma nova mulher nunca serão o resultado de uma ação mecânica, mas apenas de um processo histórico e social profundo e complexo. Um novo homem nasce pouco a pouco, gradualmente; ele não nasce adulto (FREIRE, 1996, p. 174).

Esse processo de conscientização crítica envolve tomar da opressão a realidade de volta para si e desvendar e desmistificar os mitos que confundem os oprimidos e garantem o domínio da opressão (FREIRE, 2001, p. 33). A aquisição da consciência crítica permite desafiar a reificação e substituí-la com a subjetivação do eu - a transformação dos seres humanos de objetos em sujeitos. Mais importante, a pessoa se torna um sujeito político dentro do qual a capaci- 
dade de contestação, o diálogo e a representação verdadeira da realidade podem ser alimentadas. Identifica-se como sujeito depois de reconhecer primeiro a sua condição como objetos e como se encontra nesta situação com outros, envolvidos coletivamente e mutuamente (FREIRE, 2001, p. 35). Para Freire, esse processo de subjetivaçáo no lugar no lugar da reificaçáo é equivalente a tornar-se humano (FREIRE, 2010, p. 72). A conscientização também está enraizada na "práxis humana", que Freire considera ser uma unidade indissolúvel entre a ação e a reflexão de um indivíduo sobre o mundo (FREIRE, 2001, p. 30). Nessa práxis revolucionária, derivada da compreensão marxista da práxis como "a mudança das circunstâncias e da atividade humana ou automudança" (MARX, 1994), é possível questionar, refletir e reconceituar a realidade, transformando-a, assim, tanto ao pensá-la de forma radical quanto por uma ação material que implica em fazer as coisas de forma diferente.

\section{Solidariedade na práxis da pedagogia crítica}

O elemento humanista marxista da libertação na pedagogia crítica exige a noção de solidariedade para transformar a prática dos oprimidos, bem como a sua posição em direção ao opressor. Para Freire, "a solidariedade verdadeira é encontrada somente na plenitude deste ato de amor, em sua existencialidade, na sua práxis. Afirmar que os homens são pessoas e que como pessoas devem ser livres, e ainda assim não fazer nada tangível para fazer esta afirmação uma realidade, é uma farsa" (FREIRE, 1970, p. 35). O uso que Jodi Dean faz do conceito de uma solidariedade refletiva, definida como uma "expectativa mútua de uma orientação responsável para relacionamento", é muito útil neste contexto (DEAN, 1995, p. 123) e pode ser vinculado à consciência crítica, bem como a possibilidade dos oprimidos estarem em solidariedade uns com os outros e, finalmente, com o opressor através de uma compreensão mais flexível do "nós" da solidariedade. Como uma práxis pedagógica crítica onde questionamento e reflexão devem também acompanhar a ação, uma solidariedade refletiva exige racionalização e construção de dissidência em seus fundamentos, de modo a fortalecer os laços através do diálogo e múltiplas vozes (DEAN, 1995, p. 132). Essa solidariedade também envolve uma conceituação do "nós" em solidariedade que é composto de vários "eus" e evita uma dicotomização de "nós" contra "eles", promovendo um reconhecimento mútuo do outro dentro do "nós". Isto é particularmente importante para a compreensão das pessoas envolvidas na solidariedade refletiva como sujeitos ("nós" como atores, com agência) e não objetos (incapazes de ultrapassar o "nós" passivo). Além disso, ela permite ainda mais flexibilidade dentro da categoria "nós" através de sua recriação e renovação constante nos atos de reconhecimento mútuo, permitindo a conexão de pessoas em solidariedade mútua através da inclusão ao invés da exclusão de outros (DEAN, 1995, p. 126). 
Mais especificamente, a conceitualização do "nós" dentro da solidariedade refletiva de Dean é importante por conta da forma como aqueles em solidariedade estáo posicionados em relação uns aos outros e aos outros/de fora. Ao invés de uma situação em que alguns são levados à solidariedade através da exclusão ou oposição a outro - geralmente um opressor - o foco sobre o reconhecimento mútuo prejudica a exclusáo como um motivo, porque ele deixa em aberto a possibilidade de uma mudança no número de membros e a transformação das posiçôes dos múltiplos "eus" dentro do grupo. Dean explica isso:

Com a percepção de que proferir "nós" não pressupóe a existência de um "eles", podemos nos afastar de categorias de identidade rígidas cujos limites são estabelecidos pelas dualidades de qualquer oposição. Isso torna possível uma abertura para dentro dos critérios de adesão. Em segundo lugar, a compreensão comunicativa de "nós" confronta a noção de exclusão, desafiando-nos a opor àqueles que tentam excluir os outros e lembrando-nos de nossas próprias falhas de incluisão. (DEAN, 1995, p. 127)

Portanto, uma solidariedade refletiva promove a solidariedade através da inclusão e não da exclusão e permite a extensão da solidariedade para com aqueles que poderiam atualmente estar fora, mas que podem ser trazidos para dentro através do reconhecimento mútuo.

Embora uma solidariedade refletiva funcione dentro do contexto pedagógico crítico, o aspecto humanista da pedagogia crítica também póe em relevância uma espécie de solidariedade que se baseia em valores humanistas que fazem ponte com as noções de razão, humanidade, ética, bem como com uma reflexão sobre o amor. Lawrence Wilde se refere a uma "solidariedade humana", como desenvolvida na obra de Erich Fromm e definida como "uma condição na qual todos os seres humanos sentem simpatia um pelo outro e estão determinados a resolver problemas de forma pacífica, através da cooperação" (WILDE, 2004b, p. 170). É muito importante trazer Erich Fromm para a conversa, especialmente na maneira que Wilde situa seu trabalho no contexto de solidariedade, porque Freire foi influenciado pela própria contextualização de Fromm no Humanismo Marxista e sua conceituação da humanidade (AZEVEDO, 2010, p. 45; FREIRE; FAUNDEZ, 1985, p. 61). O fato de que as obras de ambos Freire e Fromm são incorporadas em uma visão e projeto humanista fornece a base para conectar a pedagogia crítica de Paulo Freire com o objetivo de solidariedade humana. O humanismo de Eric Fromm é realmente muito perto de Freire, especialmente no entendimento de que "se opõe a todas as estruturas sociais antagônicas que reproduzem a exploração e a opressão" (WILDE, 2004a, p. 145). Fromm exorta as pessoas a escolher um "caminho produtivo" na vida, baseado no desenvolvimento de potencialidades humanas como amor, razão e trabalho produtivo, e que pode levar à sua realização por fomentar relaçóes e solidariedade com outros seres humanos (WILDE, 2007, p. 
178). Fromm adota uma visão normativa do que é (ou deveria ser) ser humano, a fim de fazer um apelo à solidariedade (WILDE, 2004b, p. 167), o que é semelhante ao ponto de Freire sobre ver a superaçáo da opressão como projeto de humanização. A solidariedade humana torna-se o caminho produtivo, enquanto que, num contexto de ódio e a permanência dentro da lógica da opressáo, isso levaria os seres humanos por um caminho regressivo.

Uma crítica potencial da solidariedade humana seria suas semelhanças com uma espécie de solidariedade afetiva, que Dean critica como limitada por depender de sentimentos, em vez de compromisso e responsabilidade. $\mathrm{Na}$ solidariedade afetiva, a motivação para agir é reduzida para o ato de se importar simplesmente porque se importar é bom ou como uma ferramenta para o desenvolvimento de uma relaçáo (DEAN, 1995, p. 116). No entanto, o foco de Fromm em um caminho produtivo que vai além de afeição ajuda a lidar com a crítica de Dean e realmente postular solidariedade humana como semelhante e compatível com a solidariedade reflexiva. Não apenas são a razão e a reflexão importantes para manter sentimentos em cheque e trazê-los para uma fruição mais significativa e de longo prazo, mas se importar é realmente um componente de solidariedade refletiva através da importância dada ao reconhecimento mútuo como a base para onde desenvolver uma orientação responsável à relação. $\mathrm{O}$ foco de Dean sobre o reconhecimento é tomado também por Juul, que elabora sobre diferentes formas de reconhecimento; um deles é o reconhecimento sob a forma de amor (JUUL, 2010 , p. 258). Um reconhecimento mútuo — um elemento principal da solidariedade refletiva na construção de um “nós” composto de vários “eus” — que é sobre o amor, os direitos e a valorização social se encaixa nos valores por trás da solidariedade humana, particularmente na forma como a luta pelo reconhecimento é também uma luta por amor (JUUL, 2010, p. 261). É também possível enxergar atores dentro da solidariedade humana que lutam por amor ao mesmo tempo em que lutam para escolher o caminho produtivo e fomentar relacionamento entre seus semelhantes. Esta conexão é bem resumida por Wilde: "Produtividade é a realização plena dos poderes humanos criativos, sem a imposição de poder sobre nossos seres humanos companheiros, bem como o desenvolvimento de relacionamentos amorosos com base na atenção, responsabilidade, respeito e conhecimento, culminando em solidariedade na base de um ideal” (WILDE, 2004b, p. 171).

Uma solidariedade humana refletiva enlaça amor e reconhecimento em um projeto humanista e é consistente com o papel da solidariedade como emancipatória dentro da pedagogia crítica. Freire ressalta continuamente que um ser humano não consegue libertar a ele mesmo ou a outro sozinho, mas que seres humanos se libertam como uma comunidade (FREIRE, 2005, p. 58), o que se alinha à solidariedade humana de Fromm.

Além disso, a práxis transformadora que está no cerne da pedagogia crítica requer valores e objetivos que são também refletivos a fim de complementar 
a ação. $\mathrm{O}$ aspecto refletivo da solidariedade, que se concentra em questionamento e raciocínio, é tão importante pedagogicamente quanto a reflexão sobre o mundo e o desafiar de dicotomias opressivas, que permite a homens e mulheres reconhecer em si uma solidariedade inseparável (FREIRE, 2005, p. 95). Esta reflexão não sujeita o amor à razáo, mas centra-se na afeiçáo, bem como a consciência crítica como fatores no aspecto responsável da orientação ao relacionamento (DEAN, 1995, p. 133). Porque esta orientação à relação também é guiada por uma práxis transformadora orientada para a superação da opressão, também pode ser dito que a solidariedade promovida através de pedagogia crítica é inerentemente política. O valor não reside na solidariedade como uma "coisa em si", mas na solidariedade como um veículo para a consciência crítica e uma visão humanista da transformação das relaçóes humanas e as estruturas de opressão.

\section{Pedagogia crítica como práxis Marxista Humanista}

O humanismo de Freire é reminiscente do de Erich Fromm na forma como fala das potencialidades humanas na linguagem do amor, generosidade e outras qualidades positivas que aprimoram o comportamento social. Enquanto esse pensamento de princípios está relacionado com a importância das escolhas de valores no humanismo marxista, devemos ter cuidado para não deixar que o otimismo mascare os muitos desafios enfrentados pelos indivíduos no processo de conscientização, os quais por vezes se materializam na difamação, violência, privação e formas de controle físicas e ideológicas. Uma perspectiva de humanização como uma vocação absoluta é prejudicial para a nossa própria sensibilidade de como homens e mulheres podem se comportar contra esta vocação de uma forma ativa, tal como no caráter afirmativo discutido por Herbert Marcuse em One-Dimensional Man (MARCUSE, 1991). Em vez disso, essa vocação deve ser contextualizada na história, a fim de reconhecer as contradiçóes reais que apontam para a natureza dialética da interação humana com seus arredores materiais. Pode-se dizer que esta vocação age de uma maneira omnilateral, em oposição à lógica unilateral do capitalismo, já que envolve tanto um posicionamento crítico em relação à hegemonia e o esforço ativo para a sua abolição (DELLA FONTE, 2014, p. 392).

O humanismo marxista e a pedagogia crítica complementam-se, mostrando que, apesar da aparência e alcance total do capitalismo, a ilusão de sua inevitabilidade é quebrada sob o conhecimento de que pessoas reais influenciam e participam da história (MCLAREN; JARAMILLO, 2010, p. 256). A exploração não é algo que ocorre fora da sociedade humana; é o vínculo real entre a natureza opressiva do capital e a realidade material dos indivíduos. $\mathrm{O}$ poder do capitalismo é derivado da capacidade de impedir o acesso a uma visão histórica da existência e, por consequência, à agência da criação e da subjetividade que separa os seres humanos de outros seres. A cognição de um indivíduo sobre sua própria humanidade (e 
as potencialidades históricas que se seguem) é um passo para tornar-se consciente de como se é oprimido. Enquanto a utopia brota do nosso desejo de nos reafirmar como seres humanos, o seu desenvolvimento tem lugar na luta material contra a opressão, já que quanto mais as pessoas sofrem mais anseiam por escapar dela. Todavia, a utopia, mantém a qualidade estática de um sonho esperançoso enquanto seu conhecimento for separado da nossa atividade prática. Para a utopia evoluir no caminho que Leszek Kolakowski argumenta, realizando o trabalho de progresso social entre momentos de ilusão e desilusão (KOLAKOWSKI, 1968, p. 151), ela deve ser a força motivadora por trás de uma práxis, cujo contínuo movimento dialético entre o que se imaginou, experimentou e pensou traz à utopia o status de uma objetividade. Isso é diferente do tipo de pensamento utópico que Kolakowski criticaria anos mais tarde, cuja visão da sociedade socialista em termos de fraternidade e igualdade nega os processos de diferenciação e desacordo que acontecem nos relacionamentos humanos em favor de um "agradável" conformismo (EPSTEIN, 2013, p. 36). Em vez disso, a utopia deve ser concebida como um desejo consciente por liberdade, o que inclui a adoção de medidas para a sua realizaçáo mesmo que o resultado final seja continuamente desafiado por mudanças na interação humana. Deste modo, a dialética náo pode ser separada da práxis autêntica, porque o seu reconhecimento funciona como uma ferramenta para revelar as dinâmicas complexas de um processo acompanhado de eventuais conflitos e contradições internas, assim como devem ser esperados da sociedade humana (KOLAKOWSKI, 1968, p. 163).

A pedagogia crítica é essencialmente ligada à visão dialética da história de acordo com como ela argumenta que a transformação pode acontecer por ação humana sob a forma de uma relação dialógica entre humanos e natureza e os seres humanos entre si em sua existência social. Quando Freire critica uma sociedade fechada, ele está realmente falando de uma expressão politicamente autoritária de hegemonia em que o pensamento e ação reificados prejudicam homens e mulheres forçando-os a uma posição antidialógica (FREIRE, 2010, p. 57). A primeira etapa para superar a opressão consiste em ser capaz de reconhecer a própria opressão, mesmo que o autoconhecimento seja prejudicado drasticamente pela situação opressiva. Isso não significa que o reconhecimento leva automaticamente à confrontação do problema (FREIRE, 2005, p. 35), especialmente porque o reconhecimento da opressão pode resultar na aceitação fatalista de invulnerabilidade do opressor; todavia, sem esse reconhecimento qualquer utopia ou estratégia revolucionária será incompleta e até mesmo distorcida. $\mathrm{O}$ fatalismo diminui as possibilidades para o diálogo porque depende da irracionalidade de um estado de dominação, mesmo quando o dominado se considera livre (FREIRE, 2010, p. 71), então prevenindo o reconhecimento. $\mathrm{O}$ que interessa aqui é tomar-se o reconhecimento como um elemento na transformaçáo da consciência reificada para uma consciência libertadora antes que uma negação fatalista da própria capacidade de mudar as circunstâncias resulte em inércia. Seria este um estado de inércia, pois transforma as pessoas em objetos, ao invés de sujeitos da história que são produzidos pelas condições econô- 
micas inevitáveis de seu tempo; não surpreendentemente, os objetos seriam como os peóes na luta de classes, a qual em si seria o que realmente move a história (em vez de a interação entre a estrutura e a agência dos seres humanos) para Louis Althusser (THOMPSON, 1978, p. 89). A inércia é desumanizante porque nega a autoria dos seres humanos em sua existência e em sua própria libertação de seus papéis como engrenagens da máquina capitalista (EPSTEIN, 2013, p. 3). Isso é prevalente quando as circunstâncias da alienação deixam a pessoa "esmagada, diminuida e acomodada, convertida em um espectador, dirigida pelo poder dos mitos que as forças sociais poderosas criar para ele/ela" (FREIRE, 2010, p. 53, tradução deste autor). Ou seja, uma pessoa muito como o homem unidimensional de Marcuse, cujo pensamento é incapaz de reconhecer a sua realidade ou cujo reconhecimento não se move criticamente em ação devido à aceitação oportunista da dominação encontrada na ilusão de melhoria de vida sob o capital (MARCUSE, 1991, p. 32).

Assim, o reconhecimento deve levar a uma luta concreta para a humanização que, em sua própria realização constitui o oposto da inércia. Marcuse afirma que a ação é também uma questão de consciência por causa da lógica dialética da libertação, onde "os escravos devem ser livres para sua libertação antes que eles possam se tornar livres, e que o fim deve estar operante nos meios para alcançá-lo" (MARCUSE, 1991, p. 41). Essa luta não pode ser feita ao imputar um certo tipo de conhecimento pseudo-revolucionário às massas ou consistentemente reafirmando que a revolução vai acontecer por ser a progressão natural da história. Para Freire, o confronto da opressão deve ocorrer em um contexto pedagógico. Ele afirma que:

Não há outro caminho senão o da prática de uma pedagogia humanizadora, em que a liderança revolucionária, em lugar de se sobrepor aos oprimidos e continuar mantendo-os como quase "coisas", com eles estabelece uma relação dialógica permanente. Trata-se de uma prática pedagógica em que o método deixa de ser, como salientamos no nosso trabalho anterior, instrumento do educador (no caso, a liderança revolucionária), com o qual manipula os educandos (no caso os oprimidos), porque já opera na própria consciência. (FREIRE, 2005, p. 63)

Essa consciência é o princípio movimentador da pedagogia crítica porque ela existe como algo que não é para si, e que está para fora dela (Freire, 2005). No entanto, a consciência por si própria significaria não mais do que uma transcendência idealista momentânea que não pode, por sua própria natureza, ser revolucionária e transformar a concretude da opressão. Marx explica esta necessidade afirmando que as ideias comunistas podem ajudar a superar a ideia de propriedade privada, mas a realidade requer a atividade comunista a fim de substituir a verdadeira propriedade privada, mesmo que este último enfrente desafios históricos, já que "o desenvolvimento que já reconhecem no pensamento como a autotranscendência na realidade envolve um processo grave e prolongado" 
(MARX, 2011, p. 149). Ao mesmo tempo em que o pensamento dialético aborda a tensão ontológica entre a realidade e o que a realidade deve ser, este pensamento decorre da prática concreta (MARCUSE, 1991, p. 133). O comunismo, como um humanismo, envolve a unidade de pensamento e prática. Uma vez que este processo de unificação é negativo, o pensamento e a prática são encontrados nas relaçóes de coerência e contradição ao longo do caminho. A reforma de consciência é parte do processo revolucionário, e que está sujeito a crises no domínio do pensamento e nas contradições com a atividade prática que são identificadas ao longo do caminho (LUKÁCS, 1971, p. 259). Enquanto pensamento/consciência fornecem os impulsos críticos para a pedagogia crítica como conscientização, a transformação da realidade segue a partir do papel da consciência crítica na práxis.

O conceito de práxis na pedagogia crítica opera da mesma forma que a noção de Karel Kosik, apesar de não existirem ligações diretas entre Freire e Kosik. $\mathrm{O}$ argumento de Kosik de que a práxis transformadora é dialética baseia-se na perspectiva da teoria e prática como uma unidade em vez de apenas vagamente ligadas nas tentativas da humanidade de explicar e mudar a realidade (KOSIK, 1976 , p. 136). Na verdade, qualquer esforço para separar a teoria da prática no marxismo negligencia os próprios argumentos de Marx na sua crítica de Feuerbach, pois ele fornece declaraçóes intransigentes sobre a natureza da atividade revolucionária como atividade histórica "prático-crítica" que une interpretação e automudança (MARX, 1994). É por isso que Kosik é obrigado a refutar a noção de práxis que é fortemente baseada na prática humana e em uma primazia da prática sobre a teoria (muitas vezes instrumentalizando a teoria no processo) nos estudos materialistas (KOSIK, 1976, p. 135). Ele estabelece que a práxis é um modo de ser que "permeia totalmente o todo do homem" (KOSIK, 1976, p. 137, ênfase no original). Porque práxis não é uma atividade isolada, mas uma atividade do ser, a prática e a teoria devem formar uma unidade dialética para não forçar à humanidade a escolha de um sobre o outro. Enquanto a prática que domina a teoria pode estagnar devido à incapacidade de reconhecer a reificação, a teoria que domina a prática impede a realização da subjetividade da humanidade: ambas as fontes de desequilíbrio iriam travar a transformação positiva da realidade. Descobertas revolucionárias só são possíveis desde que a teoria e a prática informem-se mutuamente, porque "o homem conhece a realidade na medida em que ele constitui uma realidade humana e age primordialmente como um ser prático" (KOSIK, 1976, p. 9, ênfase no original). Portanto, é de fundamental importância que a teoria seja entendida como construída sobre a cognição e não na contemplação.

A perspectiva da práxis como uma relação dialética entre teoria e prática em um movimento transformador da realidade é fortemente baseada em Marx, uma vez que refuta a interpretação materialista vulgar da práxis que vê o pensamento apenas como uma influência orientadora sobre a atividade material, prática, da humanidade. Pelo contrário, Marx argumenta que a afirmação da humanidade no mundo objetivo é composta de todos os sentidos, incluindo o pensamento (MARX, 
2011, p. 133). A pedagogia crítica estabelece que a práxis é humanização e que a humanização só pode ter lugar na práxis se for para evitar uma mistificação excessivamente otimista do potencial humano. Os seres humanos só autoafirmam sua capacidade progressiva quando eles transformam a consciência e a realidade concomitantemente. A libertação da humanidade da alienação é autêntica somente quando ela é "humanização em processo", ao invés de algo que pode ser "depositado" em indivíduos passivos (FREIRE, 2005, p. 77). A consciência crítica não pode ser imputada, só adquirida, de modo que qualquer ação que a siga torna-se a materialização do pensamento e da vontade humana. Como uma expressáo da razão dialética, ela orienta a ação para a mudança, e, desta forma, já opera como realidade transformada. Para este efeito, Marcuse argumenta que "o socialismo deve tornar-se realidade com o primeiro ato da revolução porque ele já deve estar na consciência e ação daqueles que realizaram a revolução" (MARCUSE, 1991, p. 41).

Esta interligação entre pensamento e ação na práxis informa o quanto a pedagogia crítica aborda a humanidade, o processo de aprendizagem e o propósito de aprender como a transformação de homens e mulheres, para que possam transformar a realidade de acordo com as ferramentas históricas disponíveis para eles — importante no reconhecimento de que a potencialidade humana é dada de acordo com a história e não como uma noção idealista de transcendência ou um resultado inevitável ditado pela ontologia humana. A pedagogia crítica avança o diálogo e esse diálogo é baseado na crença de que a humanidade é capaz de criar e transformar a realidade, uma capacidade limitada pela alienação (FREIRE, 2005, p. 94). Por meio de uma pedagogia dialógica, os indivíduos aprendem a questionar a sua própria alienação não porque lhes é dito, mas porque eles se tornam conscientes de sua existência dentro das circunstâncias da alienação. Eles são capazes de criticamente olhar para a sua situação para descobrir que sua luta com a exploração existe por causa do efeito condenatório da opressão às faculdades humanas. Quando Marx menciona a mortificação dos trabalhadores, ele o faz porque a sua posição ou consiste de tal morte que eles são incapazes de ver além dela ou tal morte exige do proletariado capacidade para procurar respostas fora dela. Em vez de simplesmente se concentrar em sua própria morte, a consciência crítica leva a uma compreensão da totalidade, onde eles acham que a alienação é um fenômeno social que experimentam uns com os outros (FREIRE, 2005, pp. 116-117). Uma vez que essa conscientização está incorporada na práxis através da esperança de reestabelecer sua humanidade, ela torna-se uma negação da opressão na forma como os trabalhadores pensam, agem, reagem, e socializam (que solidifica a consciência de classe e solidariedade de classe). E assim ação e reflexão interagem como uma unidade dialética, cujo movimento revolucionário é guiado pela influência da teoria revolucionária, uma estruturada em torno da agência humana sob a complexidade do caráter totalizante do capitalismo. Já que a pedagogia crítica é um método filosófico, então o humanismo marxista deve ser a filosofia que ultrapassa a pura contemplação, e que nos seus objetivos e capacidade de transformação, opera como uma filosofia da práxis. 


\section{Considerações finais}

Marx afirma que a práxis é a coincidência entre a atividade humana e a mudança da realidade e que esta transformaçáo implica igualmente na realização de uma verdadeira consciência (FROMM, 2011, pp. 21-22; MARX, 1994, p. 99). Porque a práxis envolve esta transformação dupla, ela é fundamental tanto na preparaçáo como na realizaçáo de atividade revolucionária; e, como tal, é de especial interesse para a organizaçáo política. Como um forte defensor de uma ligação deliberada entre a pedagogia e as açóes do partido político revolucionário, o pensamento político de Gramsci pode ser ligado à perspectiva educacional de Freire e vice-versa (MAYO, 1996, pp. 149-150). A revolução não é um processo mecanicista, mas um que envolve a autocapacitação orgânica dos oprimidos através do reconhecimento e da vontade de mudar (expresso em uma vontade coletiva) feito em conjunto com os representantes intelectuais orgânicos deste grupo (FORGACS, 2000, p. 310; 312). Este trabalho é executado tanto como atividade educadora como direta no âmbito pedagógico crítico, e na relação dialógica entre líderes e no grupo que representam. O objetivo é trazer a consciência teórica e prática do grupo em alinhamento de modo que o senso comum produzido e reproduzido sob a hegemonia possa ser confrontado com o propósito de também trazer outros para um questionamento sob posição crítica.

A educação dos oprimidos só é frutífera quando adotada com propósito, com o objetivo de se tornar uma autoeducação num quadro libertador. Além disso, a relação dialética entre teoria e prática prospera quando é uma expressáo da interação produtiva dialógica entre intelectuais e trabalhadores. Ela sugere uma relação solidária, em que a liderança revolucionária pensa com os oprimidos, e não em torno dos oprimidos, como constitutivo de um "nós" inclusivo. No geral, uma perspectiva pedagógica de organização política é adequada dentro do $\mathrm{Hu}$ manismo Marxista porque se opóe ao relacionamento doutrinário dos detentores do conhecimento para com os proprietários do trabalho, como encontrado no comunismo vulgar, e busca estabelecer um diálogo entre a atividade intelectual e prática, mesmo que seja importante ter pessoas cuja principal função na sociedade é intelectual. A perspectiva encarna a práxis precisamente porque renuncia a separação entre teoria e prática que sempre mantém o proletariado em uma posição de subserviência, seja para o capitalista ou ao líder do partido.

A compreensão da práxis na pedagogia crítica como um veículo revolucionário político preenche o Humanismo Marxista em todos os níveis de análise, da ausência de práxis na existência alienada, para a unificação da teoria e prática como uma estratégia para a mudança e o culminar real da revoluçáo. O espaço da liberdade deve ser da práxis em ordem para que a humanidade mantenha a sua subjetividade e o elemento solidário a promove como um processo coletivo de libertaçáo. Sem a práxis, uma sociedade livre seria gradualmente devolvida a um estado desumaniza- 
dor, uma vez que as potencialidades humanas são mais propensas a florescer quando as capacidades conscientes estáo em linha com a atividade prática quando refletida na criatividade, raciocínio crítico, solidariedade e esforço produtivo.

\section{Notas}

1. O artigo original em inglês trata dos termos "opressor" e "opressed" de forma neutra em gênero de acordo com as normas e possibilidades oferecidas pela língua inglesa. No português, a tradução foi feita como "opressor" e "oprimido" de forma a se conformar às normas plurais do português culto, o qual, infelizmente, produz e reproduz a hegemonia do gênero masculino em sua linguística. A autora, portanto, deseja comunicar que as categorias de que trata são interseccionais em si e no contexto geral de opressão explorado no texto devem ser entendidas como abrangente de todos os gêneros apesar da forma culta da língua.

\section{Referências}

ALLMAN, P. Revolutionary social transformation: democratic hopes, political possibilities and critical education. Westport: Bergin \& Garvey, 1999.

ARONOWITZ, S. Paulo Freire's radical democratic humanism. Em: MCLAREN, P.; LEONARD, P. (Eds.). Paulo Freire: a critical encounter. London: Routledge, 1993.

AZEVEDO, J. A. Fundamentos filosóficos da pedagogia de Paulo Freire. Akrópolis Umuarama, v. 18, n. 1, p. 37-47, 2010.

DEAN, J. Reflective Solidarity. Constellations, v. 2, n. 1, p. 114-140, 1995.

DELLA FONTE, S. S. A formação humana em debate. Educação \& Sociedade, v. 35, n. 127, p. 379-395, 2014.

EPSTEIN, B. The Rise, Decline and Possible Revival of Socialist Humanism, 2013.

FREIRE, P. Pedagogy of the Oppressed. New York: The Seabury Press, 1970.

. Letters to Cristina: reflections on my life and work. Tradução Donaldo Macedo; Quilda Macedo; Alexandre Oliveira. London: Routledge, 1996.

. Conscientização: teoria e prática da libertação. São Paulo: Centauro Editora, 2001. . Pedagogia do Oprimido. 49 ed. Rio de Janeiro: Paz e Terra, 2005.

. Educação como prática da liberdade. São Paulo: Paz e Terra, 2010.

FREIRE, P.; FAUNDEZ, A. Por uma pedagogia da pergunta. 4 ed. Rio de Janeiro: Paz e Terra, 1985.

FROMM, E. Marx's concept of man. Mansfield Centre: Martino Publishing, 2011.

FORGACS, D. (Ed) The Antonio Gramsci reader: selected writings, 1916-1935. New York: New York University Press, 2000. 
GRAMSCI, A. Prison Notebooks: Volume III. Tradução Joseph A. Buttigieg. New York: Columbia University Press, 2007.

JUUL, S. Solidarity and Social Cohesion in Late Modernity: A Question of Recognition, Justice and Judgement in Situation. European Journal of Social Theory, v. 13, n. 2, p. 253269, 2010.

KOLAKOWSKI, L. Toward a Marxist Humanism. New York: Grove Press, 1968.

KOSIK, K. Dialectics of the concrete: A study on problems of man and world. Boston: D. Reidel Publishing Company, 1976.

LUKÁCS, G. History and class consciousness: studies in Marxist dialectics. Cambridge, Mass: MIT Press, 1971.

MARCUSE, H. One-dimensional Man. Boston: Beacon Press, 1991.

MARX, K. Theses on Feuerbach. In: SIMON, L. H. Selected writings. Hackett Publishing Company, 1994.

Economic and Philosophic Manuscripts of 1844 . Tradução T. B. Bottomore. Mansfield Centre: Martino Publishing, 2011.p. 87-170

MAYO, P. Transformative adult education in an age of globalization: A GramscianFreirean synthesis and beyond. The Alberta Journal of Educational Research, v. 42, n. 2, p. 148-160, 1996.

. Liberating praxis: Paulo Freire's legacy for radical education and politics.

Westport: Praeger Publishers, 2004.

MCLAREN, P.; JARAMILLO, N. E. Not Neo-Marxist, Not Post-Marxist, Not Marxian, Not Autonomist Marxism: Reflections on a Revolutionary (Marxist) Critical Pedagogy. Cultural Studies/Critical Methodologies, v. 10, n. 3, p. 251-262, 2010.

THOMPSON, E. P. The poverty of theory. In: THOMPSON, E. P. The poverty of theory \& other essays. New York: Monthly Review Press, 1978. p. 1-205.

TORRES, C. A. Diálogo com Paulo Freire. 3 ed. São Paulo: Edições Loyola, 1979.

WILDE, L. Conclusion: Radical Humanism and Human Solidarity. In: WILDE, L. Erich Fromm and the Quest for Solidarity. New York: Palgrave Macmillan, $2004 \mathrm{a}$.

. A "Radical Humanist" Approach to the Concept of Solidarity. Political Studies, v. 52, n. 1, p. 162-178, 2004 b.

. The Concept of Solidarity : Emerging from the Theoretical Shadows ? British Journal of Politics and International Relations, v. 9, n. 1, p. 171-181, 2007.

Recebido em 22 de setembro de 2014.

Aprovado em 10 de novembro de 2015. 